\title{
PARA ALÉM DA DONA DE CASA: O TRABALHO DAS MULHERES DE BAIXA RENDA NA DINÂMICA DA INFORMALIDADE
}

Jaqueline Melo ${ }^{1}$

Tatiane Lucia De Melo ${ }^{1}$

${ }^{1}$ Pontifícia Universidade Católica de Minas Gerais - PUC Minas 


\section{PARA ALÉM DA DONA DE CASA: O TRABALHO DAS MULHERES DE BAIXA RENDA NA DINÂMICA DA INFORMALIDADE}

Resumo: O segmento informal possui grande importância no Brasil e no mundo e a força de trabalho feminino carrega boa parte dos envolvidos nesse processo. As mulheres, devido às obrigações sociais que envolvem os papéis de gênero, necessitam frequentemente conciliar o trabalho, o estudo e as tarefas domésticas. Um recorte relevante e pouco estudado diz respeito à sobrevivência e mortalidade desses empreendimentos. Embora existam pesquisas sobre o tema da mortalidade, estas são voltadas para a análise de empresas formalmente constituídas. O presente trabalho, cujo público foi exclusivamente do sexo feminino, buscou a partir da literatura existente avançar na busca das causas de sobrevivência e mortalidade dessas atividades produtivas informais. Para isso, foi realizada adaptação das categorias (indivíduo, atividade, ambiente) sendo utilizadas na análise de quatro atividades produtivas urbanas. Resultados permitem constatar a noção de que esses empreendimentos são dotados de lógica peculiar, exigindo revisão de alguns conceitos analíticos e novas pesquisas.

Palavras-chave: Informalidade. Mulheres. Empreendedorismo. Trabalho.

\section{$1 \quad$ Introdução}

A pobreza é fenômeno complexo (Sen, 2010), com múltiplas dimensões e facetas associadas, por exemplo, à desigualdade, à exclusão e à informalidade (Márquez, Reficco \& Berger, 2010). Nesse contexto, questões envolvendo trabalho e renda adquirem relevância ímpar. Assegurar trabalho "decente" - compreendido como o respeito aos direitos e princípios fundamentais no trabalho -, salienta Leone (2010), é componente essencial para a promoção do desenvolvimento socioeconômico, a redução das desigualdades sociais e o combate à pobreza. De fato, pobres e vulneráveis buscam principalmente no emprego o caminho para sair da pobreza (Banco Mundial, 2015). No entanto, atualmente, mais de um bilhão de pessoas em idade ativa não estão participando da força de trabalho formal. Muitas delas acabam por se verem obrigadas a buscar, na atividade produtiva informal, fonte alternativa de renda (Banco Mundial, 2015).

Com efeito, salientam Warren (2003) e Maia (1999) como, na maioria dos países, subdesenvolvidos ou mesmo desenvolvidos, prolifera vasta gama de atividades econômicas que, a par das obrigações tributárias, deixam de pertencer ao mercado formal. No Brasil, a realidade não é diferente. Segundo dados mais recentes do Ministério da Fazenda (2010), há mais de 10 milhões de empreendimentos informais no país. Eles englobam complexo e heterogêneo conjunto de atividades produtivas - formadas por autônomos, camelôs, donos de pequenas oficinas, botecos, etc -, e variam de atividades artesanais até a composição de iniciativas pré-capitalistas com potencial de expansão (Pochmann, 2008).

Os temas da mortalidade de empresas e da informalidade no segmento de baixa renda vêm, de maneira isolada, sendo objeto de inúmeras pesquisas no Brasil. Em relação ao primeiro, devido, em grande parte, a pesquisas capitaneadas pelo Sebrae. Desde 1908, a 
instituição monitora a sobrevivência de novos empreendimentos no país (sobre este tema, ver por exemplo: SEBRAE, 2011; Vale, Aguiar \& Andrade, 1998). Atualmente, a temática tem sido objeto de análise de diferentes estudos (Albuquerque, 2013; Cazarini e Braga, 2008; Dias, Gonçalves e Augusto, 2014; Dutra e Previdelli, 2005). Em relação ao segundo, devido pesquisas conduzidas por diferentes autores (ver, por exemplo: Gomes et al., 2005; Leone, 2010; Pamplona, 2002; Rakowski, 1994; Santos et al, 2014; Theodoro, 2000; Viana et al, 2013, Warren, 2003, entre outros). Valarelli e Vale (1997), por exemplo, conduziram um dos estudos pioneiros sobre a informalidade no Brasil. Eles buscaram compreender a natureza e dinâmica de pequenos estabelecimentos produtivos informais localizados nas favelas e periferias da cidade do Rio de Janeiro.

Apesar do crescimento das pesquisas sobre os temas nos últimos anos, estes vêm sendo conduzidos, principalmente, por economistas e sociólogos. Tais temáticas não mereceram, ainda hoje, a devida atenção no contexto dos estudos organizacionais. Com efeito, em pesquisa realizada em alguns dos principais periódicos (RAC, RAE, O\&E e Rausp) e congressos de administração no Brasil (EnAnpad, Eneo, Egepe, Semead), não foram encontrados trabalhos que buscassem compreender, de maneira integrada - tal como aqui almejado -, sobre a dinâmica envolvida na mortalidade e informalidade de empresas, especialmente no que tange ao papel da mulher nesse contexto. Tal lacuna é ainda mais evidente quando se associa ambos os temas na investigação de um contexto específico, o de atividades produtivas femininas inseridas em segmentos de baixa renda, aqui de interesse particular. Este artigo, uma inovação nos estudos de administração, insere-se justamente aí. Procura preencher parte desta lacuna de pesquisa. Faz isto através do estudo das causas de sobrevivência e mortalidade das atividades produtivas informais imersas no segmento de baixa renda e o papel das mulheres em seu contexto histórico. Neste trabalho, compreende-se atividades produtivas informais como aquelas conduzidas por indivíduos/empreendedores movidos pela necessidade de sobrevivência (GEM, 2011). Isto é, indivíduos que, sem alterativas melhores de emprego e renda, acabam por se verem obrigados a criarem pequenas unidades produtivas de subsistência, visando seu sustento e o de suas famílias.

Este artigo encontra-se dividido como segue. Na primeira parte, apresenta o referencial teórico. Nele, associa-se o tema da informalidade com o da sobrevivência e mortalidade de empresas. A partir daí, edifica-se modelo teórico de análise, utilizado como referência para a análise dos dados. A segunda parte delineia a metodologia e os resultados obtidos. Finalmente, nas considerações finais, reflete-se sobre a natureza particular da dinâmica e da lógica de empreendimentos informais, tecendo contribuições teóricas inéditas às categorias e conceitos analíticos vigentes.

\section{$2 \quad$ Referencial Teórico}

\subsection{A revolução industrial: o início das transformaçães no mundo trabalho}

A Revolução Industrial teve início na Inglaterra no século XVIII e caracterizou-se por um conjunto de transformações econômicas e sociais que levaram à aceleração do crescimento. A expansão do comércio e dos centros urbanos culminaram em um aumento da demanda de consumo. (HOBSBAWM, 2000). 
As mudanças nas cidades impactavam a vida no campo, transformando o cotidiano de milhares de mulheres camponesas, acostumadas até então a uma rígida divisão de papeis e espaços, especificamente o da casa e da criação de animais. Com as transformações ocorridas a partir do século XVIII, a vida nos campos muda, afetando diretamente a vida das mulheres. O êxodo rural, bem como as guerras (principalmente a I Guerra), acabaram por esvaziar os campos do trabalho de homens jovens e designando estas funções para as mulheres. Assim, elas aprenderam a lavrar a terra e passaram a gerenciar os negócios. Tais mudanças modificaram o equilíbrio das famílias e as relações entre os sexos. (PERROT, 2017).

As transformações não ocorreram apenas na vida das mulheres camponesas. Se, por um lado, havia aquelas que assumiam o lugar dos homens na produção agrícola, também existiam as mulheres que participavam do êxodo rural, visto que seus pais, que até então as colocavam como criadas em propriedades rurais ou na cidade, passaram a buscar o trabalho nas fábricas. Essas fábricas empregavam as moças desde os 14 anos, e estas ali permaneciam por muitos meses sem ir para a casa, e suas famílias é que recebiam diretamente o seu salário. (PERROT, 2017a, p. 113).

Rago (2017) nos oferece importantes informações sobre o ingresso de mulheres nas fábricas no contexto dos primórdios da industrialização brasileira. Eram, em sua maioria, vistas como "mocinhas infelizes e frágeis", sendo emocionalmente vulneráveis para os que as cercavam e, consequentemente, se tornando presas das ambições masculinas dos colegas de trabalho e dos patrões.

Isso significa que lidamos muito mais com a construção masculina da identidade das mulheres trabalhadoras (dessa época) do que com sua própria percepção de sua condição social, sexual e individual. Não é atoa que até recentemente, falar das trabalhadoras urbanas no Brasil significava retratar um mundo de opressão e exploração demasiada, em que ela apareciam como figuras vitimizadas e sem nenhuma possibilidade de resistência. Sem rosto, sem corpo, a operaria foi transformada numa figura passiva, sem expressão política nem contorno pessoal. (RAGO, 2017, p. 579)

No século XVIII e XIX a mulher, principalmente das camadas populares, se dividiu entre o trabalho fabril e as atividades domésticas. A exploração da mulher que era exclusividade do marido passou a ser explorada também pelo capital. Nessa época, muitas mulheres eram costureiras e completavam o orçamento doméstico trabalhando em casa, às vezes até 18 horas por dia para fábricas de chapéus. (RAGO, 1997/2017).

O Brasil do final do século XIX era um país de profundas raízes escravagistas, e que ainda mantinha em suas entranhas a estrutura da Casa Grande, onde os negros (sejam mulheres ou homens) eram percebidos como indivíduos com habilidades grosseiras e percepção limitada. A mão de obra disponível, apesar de ser encontrada em grande escala, não tinha a qualificação e as habilidades necessárias para as atividades industriais. De acordo com Rago (1997/2017), as políticas de incentivo a imigração promovidas pelo governo brasileiro, bem como a vida difícil em seus países de origem, fizeram com que espanholas, portuguesas, italianas, alemãs, romenas, polonesas, húngaras, lituanas, sírias e judias migrassem para o Brasil para trabalharem nas fábricas.

Nesse contexto de mudanças na estrutura econômica e social, ocorrida em níveis globais, vemos surgir no curso da Revolução Industrial uma nova classe: o proletariado, e, 
junto com ele, suas ideologias e movimentos (Hobsbawn, 2000). É esta classe, com seus homens, mulheres e crianças pobres que necessitam de meios para prover o seu sustento, que surge a mola propulsora dos trabalhos nas indústrias.

Como veremos adiante, no início do século XX essa divisão de classes evidencia não apenas diferenças sociais entre mulheres, mas também entre os trabalhos nos quais elas irão se envolver. Às mulheres pobres, proletárias, cabia o manuseio da terra e o chão das fábricas, às mulheres burguesas, o espaço doméstico. (HOBSBAWN, 2000; PERROT, 2017A; PERROT, 2017B)

\subsection{A burguesia e o controle do corpo feminino: espaço doméstico e a romantização da maternidade}

Durante o século XIX a sociedade brasileira vivenciou uma série de transformações, dentre elas a consolidação do capitalismo, o que proporcionou o crescimento da vida urbana e de novas alternativas de convivência social, promovendo também a ascensão burguesa e o surgimento de uma nova mentalidade reorganizadora das vivências familiares e domésticas, do tempo e das atividades femininas. (D'INCAO, 1997/2017, P. 223).

Como se percebe, a proposta burguesa era de criar novos parâmetros sociais, com papeis bem definidos entre os atores. E, nesse sentido, a divisão sexual se torna mais evidente, principalmente a do trabalho, como nos confirma Perrot (2017b). Ou seja, à mulher era destinado o espaço doméstico, de organização da casa e cuidado para com os filhos. Para o homem, o espaço público do trabalho e o lugar de provedor e cuidador da família. (Hobsbawn, 2000). Assim, presencia-se neste período o nascimento da valorização da intimidade e da figura materna associada à mulher, que passa então a ser a responsável por manter um sólido ambiente familiar, a educar os filhos e dedicar-se ao marido, desobrigada de qualquer trabalho produtivo, representando o ideal de retidão e probidade, um tesouro social imprescindível. (D’INCAO, 1997/2017, P. 223).

Nesse contexto, a maternidade adquire, junto com a ascensão burguesa, um status de centralidade na vida da mulher, garantindo a sucessão da reprodução familiar e os futuros herdeiros. Por outro lado, o cuidado dos filhos e da casa não era algo exclusivo às mulheres pertencentes às classes mais favorecidas. As mulheres pobres, as operárias, as mulheres do campo, também tinham essa obrigação, muitas vezes pelo fato de não ter com quem deixar os seus filhos. O homem na fábrica, a mulher em casa, ocupando-se do doméstico (Perrot, 2017b). As operárias eram acompanhadas pelos seus filhos nas fábricas, sendo que os mesmos começavam a trabalhar assim que apresentavam condições. (RAGO, 1997/2017).

\subsection{A explosão urbana e as transformações no mundo do trabalho}

O dinamismo social provocado pelo crescimento acelerado das cidades e das fábricas promoveu a ruptura do espaço doméstico como demarcação do ambiente onde a mulher deveria estar. A função de ir aos pontos de comércio, de transitar pela cidade em busca de suas necessidades, e até mesmo de trabalhar em outras casas para completar o orçamento do marido se tornaram tarefas femininas, permitindo à mulher começar a se apropriar dos espaços urbanos. (PERROT, 2017b). 
Mesmo com a permanência da ideia de que a mulher deveria casar e ter filhos (Santos, 2012), havia um processo de desenvolvimento econômico em curso que exigia das mulheres mais do que as habilidades que se acreditava virem de berço. Essa mulher agora precisa gerir salários, coordenar as necessidades da casa e cuidar para que os filhos (principalmente os homens) dominassem as tarefas da escola. Todas essas transformações vinham trazendo a tona um questionamento decorrente do processo iniciado a partir dos séculos XVIII-XIX nas sociedades ocidentais, provocado pelo regime assalariado e pela industrialização: as mulheres deveriam sair de casa, abandonar o lar que era o seu ponto de apoio e utilidade, para terem acesso a salário, serem remuneradas pelo seu trabalho? (PERROT, 2017a)

A resposta veio com o transcorrer do tempo e com a evolução, mesmo a passos lentos, das sociedades urbanas. A participação da mulher nas atividades remuneradas intensificou-se a partir da década de 80, principalmente entre as camadas mais baixas da população, devido à necessidade de complementação do orçamento familiar e garantia da sobrevivência, em meio a um cenário de incertezas. $\mathrm{O}$ que se percebe é que a entrada da mulher no mercado de trabalho esteve relacionada ao empobrecimento da população e a geração de renda, e não necessariamente por uma ampliação das oportunidades de trabalho. (SANTOS, 2012).

Se, por um lado, houve transformações no perfil e nas características do universo feminino no contexto do trabalho, pode-se dizer que isso também se estendeu as relações de trabalho e geração de renda. O crescimento do trabalho formal, com a regularização trabalhista de certas atividades outrora informais, como a de diarista, por exemplo, o surgimento de novas formas de geração de renda ampliou o horizonte de atuação feminino.

Este breve percurso histórico teve o objetivo de contextualizar o trabalho feminino no último século para auxiliar na compreensão das atividades atuais de trabalho que envolvem as mulheres de baixa renda. Como será visto a seguir, esses modos contemporâneos de trabalho trazem algumas inovações em suas propostas, mas carregam consigo a manutenção de traços e características do que foi vivenciado pelas mulheres pobres ao longo do século XX.

\subsection{Trabalho informal: uma alternativa para mulheres?}

Em meados dos anos 70, o termo "setor informal" passou a fazer parte do jargão oficial. Criado no seio da Organização Internacional do Trabalho (OIT), tal conceito aparece como novo instrumento explicativo para um velho fenômeno: a existência de atividades econômicas de baixa produtividade e que se desenvolvem à margem da legislação (Ferreira, 2009). Ao longo dos anos, o debate sobre o setor informal tem aumentado em complexidade (Rakowski, 1994).

A partir dos anos 2000, a informalidade no segmento de pequenos negócios - até então expressão de problemas históricos e estruturais de uma economia em desenvolvimento - passou a resultar, também, da estagnação relativa da economia brasileira (Santos, Krein, Calixtre, 2012). Visando reverter esta situação, diferentes iniciativas públicas e privadas passaram a serem edificadas nos últimos 20 anos. Inserem-se aí aquelas conduzidas pelo Sistema Nacional de Empregos (SINE), pela hoje extinta Legião Brasileira de Assistência (LBA), e mais recentemente pelo o Conselho Deliberativo do Fundo de Amparo ao Trabalhador (CODEFAT) e pelo Banco Nacional de Desenvolvimento Econômico e Social (BNDES). (THEODORO, 2000). 
Com o objetivo de retirar da informalidade milhões de empreendedores e facilitar a abertura de novos negócios, o SEBRAE instituiu a figura do 'Empreendedor Individual' (EI). Com ela, empreendedores que faturam até $\mathrm{R} \$ 60.000,00$ (Sessenta mil reais) por ano, não possuem participação em outra empresa como sócio ou titular e que empregam até um trabalhador podem se formalizar como EI (VIANNA, TEIXEIRA, \& FRANCA, 2013).

A despeito das diversas iniciativas de apoio ao empreendedorismo informal, diferentes motivos impactaram, ainda assim, em aumento do número de empreendimentos informais no Brasil nos últimos anos (Santos, 2006; Santos et al., 2012). Inserem-se, aí: reduzida qualificação profissional, baixa instrução formal e pouco capital acumulado (Santos et al., 2012). Com efeito, muitos empreendedores informais são, ao mesmo tempo, movidos por necessidades. Isto é, influenciados pela incapacidade de encontrarem melhores alternativas de trabalho e renda, muitos indivíduos acabam por se veem obrigados a criarem pequenos empreendimentos, usualmente informais, como forma de sobrevivência. Conquanto possam gozar de certas similaridades com os empreendimentos formais, negócios informais tendem a possuir diferentes particularidades. Salienta Montenegro (2013), por exemplo, como tais empreendimentos, por se concentrarem em parcelas desvalorizadas do tecido urbano e por possuírem baixo nível de capitalização, necessitam de escala mínima de mercado, suficiente para permitir perpetuar sua existência.

Neste sentido, seriam as redes locais as responsáveis por sustentar os empreendimentos. De fato, salienta Marques (2010) como a participação em determinadas redes de sociabilidade desdobra-se, muitas vezes, na prestação de pequenos serviços entre os próprios membros das redes. Além disso, diferentes outros fatores associados à peculiaridade de empreendimentos informais poderiam, também, se inserir ai. Destacam-se, por exemplo: i.) grande vulnerabilidade; ii.) precariedade de recursos; iii.) instabilidade produtiva; iv.) caráter refratário a mecanismos convencionais de políticas públicas; v.) ausência de alternativas; vi.) heterogeneidade; vii.) pequena escala; viii.) ausência de distinção entre capital e trabalho; ix.) baixa produtividade, entre outros.

Não obstante, pesquisas sobre mortalidade no segmento de microempresas estariam mais próximas do universo de interesse do presente trabalho. As microempresas situar-se-iam, algumas vezes, em uma fronteira eventualmente movediça e fluida entre os segmentos informal e formal. De fato, alguns autores fazem menção a essa zona de transição entre a atividade informal e a microempresa (Valarelli \& Vale, 1997). Salientam como, em contextos desfavoráveis, microempresas podem passar à informalidade. Da mesma maneira, em contextos muito favoráveis, pequenas unidades produtivas informais, inclusive as de baixa renda, podem se formalizar, transformando-se em microempresas ativas no mercado (VALARELLI \& VALE, 1997).

O presente estudo analisou 26 artigos que abordam as temáticas no segmento de micro, pequenas e médias empresas (Albuquerque, 2013; Cazarini et al., 2008; Eckert, Mecca, Blasio, \& Macari, 2013, entre outros). O número de artigos se baseou na saturação teórica. Sua seleção foi feita com base em palavras chave nos títulos dos trabalhos. Foram identificados e analisados os motivos ou fatores intervenientes no processo de sobrevivência ou mortalidade. Da análise, foi possível elencar amplo conjunto de variáveis associados ao fenômeno. A partir daí, buscou-se classificar e agrupar as variáveis teóricas em conjuntos de categorias. Para isso, utilizou, em primeiro momento, o modelo proposto por Ferreira, Santos, 
Oliva, Grisi e Lima (2012). Nele, os fatores de sobrevivência e mortalidade poderiam ser condensados em três grandes grupos, a saber: a) inerentes ao empreendedor; b) relativos ao negócio; e c) relacionados ao ambiente externo do negócio.

À luz das análises do setor informal até aqui apresentadas, é possível afirmar, à princípio, serem as atividades informais dotadas de dinâmica diferenciada, particular. Uma delas é a de que os setores informais seriam caracterizados por unidades produtivas pequenas, compostas, muitas vezes, por única pessoa (o dono, ou empreendedor ou autônomo). Quando imersos, ao mesmo tempo, em comunidades de baixa renda (periferias ou favelas), tais indivíduos se caracterizariam, também, por possuírem baixa escolaridade, pouca ou nenhuma experiência ou trabalho assalariado. Além disso, explorariam atividades voltadas principalmente à própria subsistência, movimentando conjunto pequeno de recursos, inclusive financeiros, e se voltando ao atendimento das necessidades dos locais onde habitam. Disto resultaria a constatação de que seus "mercados" seriam, de maneira geral, restritos, isto é, limitados, muitas vezes, a conhecidos, amigos e associados.

Levando-se em consideração tais peculiaridades, foi-se edificado, a partir de quadro proposto por Ferreira et al. (2012), novo modelo categórico, mais aderente às características e peculiaridades do segmento informal. Diante disto, as categorias propostas por Ferreira et al. (2012) - Empreendedor, Negócio e Ambiente Externo - adequadas à análise de empreendimentos formais, foram ajustadas, considerando-se o caráter muitas vezes precário, pouco estruturado e instável das atividades informais. Da análise, criou-se três novas categorias, denominadas: i.) indivíduo (ou empreendedor); ii.) atividade produtiva (ou negócio), e; iii.) ambiente socioeconômico (ou ambiente externo). O resultado dessas reflexões, advindos do cotejamento entre, por um lado, as características do segmento informal e, por outro, as categorias e fatores de sobrevivência e mortalidade, permitiram a elaboração de modelo preliminar de análise para o fenômeno de interesse (Quadro 1).

Quadro 1. Categorias de análise propostas e respectivos fatores associados

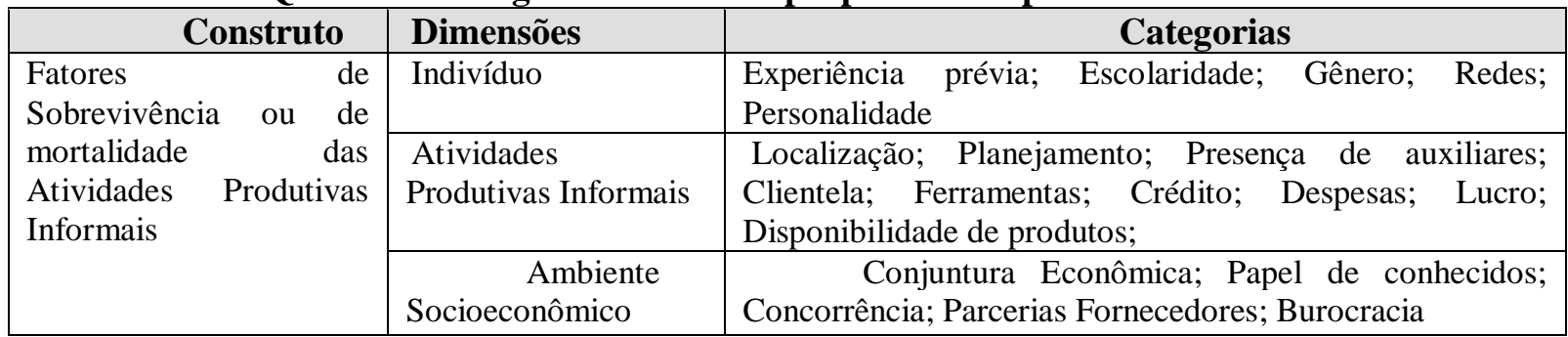

\section{Fonte: Elaborado pelas autoras}

Cabe ressaltar que, atualmente, o trabalho informal contempla uma parte significativa da mão de obra brasileira, sendo difícil a mensuração deste setor devido a multiplicidade de atividades que ele pode englobar. Seja pela sobrecarga de tarefas, pela oportunidade de renda extra e autonomia para pessoas com pouca ou nenhuma qualificação, sendo destacada a facilidade de horários de trabalho, a flexibilização do tempo e do modo de trabalhar valorizando os espaços de negócios como ambientes de convivência social e amizades, este é um setor da economia na qual encontramos a presença de muitas mulheres. (Costa, 2007). Nesse sentido, Bruschini (2006) nos auxilia a compreender essa participação trazendo um panorama dos estudos de trabalho e gênero no Brasil: 


\begin{abstract}
De um lado, a intensidade e a constância do aumento da participação feminina no mercado de trabalho, que tem ocorrido desde a metade dos anos 1970, de outro, o elevado desemprego das mulheres e a má qualidade do trabalho feminino; de um lado a conquista de bons empregos, o acesso a carreiras e profissões de prestígio e a cargos de gerência e mesmo diretoria, por parte de mulheres escolarizadas, de outro, o predomínio do trabalho feminino em atividades precárias e informais. (Bruschini, 2006, p.538)
\end{abstract}

Todavia, a questão de gênero é um fator que gera dificuldades na inserção das mulheres no mercado formal de trabalho, principalmente quando se trata de mulheres pobres e de baixa escolaridade. A baixa perspectiva para empregos com boa remuneração, a sobrecarga causada pelo acumulo com as tarefas domésticas e a falta de politicas sociais de apoio ao cuidado dos filhos geram uma contínua instabilidade e exposição a pobreza. (COSTA, 2007).

\title{
3. Metodologia, Resultados e Discussão
}

A estratégia de pesquisa foi qualitativa (ver: Gaskell, \& Allum, 2002; Creswell, 2007; Gaskell, 2002; Godoy, 1995, Godoy, 2005; Minayo, Souza, \& Santos, 2005). De natureza descritiva (Godoy, 2006; Ridder, Hoon, \& McCandless, 2009; Yin, 2010), tal pesquisa é indicada às investigações que visam descrever fenômenos dentro de seu contexto (Ridder et al., 2009). O método utilizado foi o estudo de caso múltiplo (Aaboen et al., 2012; Eisenhardt, 1989; Godoy, 2006; Ridder et al., 2009).

As categoriais citadas anteriormente embasaram a construção das categorias finais, sendo as mesmas constituídas por três grandes grupos denominados: "Indivíduo", "Atividades produtivas informais" e "Ambiente Sócio Econômico". As unidades empíricas de análise foram quatro unidades produtivas informais localizadas na Região Metropolitana de Belo Horizonte e beneficiárias do Programa de "Apoio ao Empreendedorismo", da Rede Cidadã.

A Rede Cidadã é uma Organização Social, de âmbito Nacional, sem fins lucrativos, cuja missão é "promover a cidadania, constituindo redes de voluntários, empresas, sociedade civil e governo, gerando maior valor social" (Rede Cidadã, 2015). Das quatro atividades produtivas investigadas, duas estavam, quando da coleta de dados, ativas há mais de dois anos, e duas estavam extintas pelo mesmo período. Observa-se que a Rede Cidadã forneceu, inicialmente, cerca de quarenta pessoas por ela atendidas (todas mulheres). Temendo discutir o assunto informalidade, dado o caráter ilegal da qual se reveste tais unidades, a maioria recusou-se a participar das entrevistas. As identidades dos empreendedores foram, por motivos éticos, preservadas. Visando manter sua privacidade, a nomenclatura adotada foi " $\mathrm{A}$ " e "B" para ativas, "C" e "D" para extintas.

Com 56 anos de idade, a primeira empreendedora "A" é divorciada e mora com uma filha de 37 anos, sua ajudante, em bairro da periferia de Belo Horizonte/MG, onde produz pães, roscas, biscoitos, salgados e marmitex para venda, garantindo o sustento de ambas. De origem modesta, foi acostumada a trabalhar nos serviços domésticos desde sua infância (com 8 anos de idade), momento em que relata ter aprendido a cozinhar apenas observando sua mãe nos afazeres da cozinha. Trabalhou em várias casas de família, onde desenvolveu algumas de suas habilidades e adquiriu alguns contatos. Com apenas a $4^{\text {a }}$ série do Ensino Fundamental, demonstra possuir garra e força de vontade. Quando pensou em trabalhar por conta própria, tomou conhecimento da Rede Cidadã, onde buscou apoio. A partir daí, ela pôde participar de 
curso de Informática e outros, além de assistir a palestras sobre temas diversos. Seu linguajar reflete seu senso de observação e, também, suas idiossincrasias.

Para ela, o conceito de lucro apresenta-se como um conceito de sobra, referindo-se a uma iniciativa para atender uma demanda grande, onde teve que se associar a outros produtores, para dividir as despesas, explica como chegou às sobras: "esse aqui sobrou, aí são as sobras. É divido em partes iguais para todos que trabalharam". Nesse mesmo relato, observa-se como consegue sobreviver sem crédito, compartilhando custos com eventuais parceiros. Seus contatos foram considerados muito importantes para a sobrevivência de seu negócio. "A" realiza a produção em sua residência e comercializa em feiras e eventos organizados por diversas instituições parceiras da Rede de Economia Solidária de Belo Horizonte, como o Instituto Paulinus, Instituto Promovendo, SEDESE, Instituto Karitas, Instituto Maristas, dentre outros. Como pontos fortes do empreendimento, "A" ressalta a presença das parcerias, especialmente da Rede Mineira de Economia Solidária e da Rede Cidadã. Como pontos de fragilidade, ela destaca a dificuldade de acesso ao crédito. Seu sonho é crescer e poder contratar mão de obra para lhe ajudar.

Com 47 anos de idade e ensino médio técnico em decoração, a segunda empreendedora "B" é divorciada e possui dois filhos, com idades de 29 e 31 anos. O interesse pela decoração é antigo, mas a atividade não começou como sua fonte de renda. Quando casada, a decoração era tida como satisfação pessoal. Quando se formou, ela teve oportunidade de assistir a uma palestra sobre Feng Shui e decidiu que era nessa linha que gostaria de trabalhar. Começou a atividade de maneira irregular, pois a vida pessoal começava a ficar desorganizada.

Após o divórcio, os filhos foram morar com o pai, ela perdeu grande parte da renda que era de aluguel, e não pôde manter as despesas. De repente se encontrou "sem teto, sem nada, sem rumo". A partir daí ela ficou fazendo pequenos "bicos", chegou a trabalhar como vendedora em uma loja de roupas. Cansada de passar dificuldades, inclusive, algumas vezes, fome, decidiu investir em seu "dom" e criou, em 2007, sua atividade produtiva de Feng Shui. Foi nesta ocasião que surgiu oportunidade de trabalhar de maneira formal. De acordo com "B", de certa forma uma empresa a obrigou a ser um negócio formal, devido à necessidade de possuir CNPJ, contador, nota fiscal, etc. Após idas e vindas, oscilando nos negócios e no nível pessoal, fechou sua empresa e começou a trabalhar como massagista, de maneira informal.

O Feng Shui, no entanto, continuou a ocupar sua imaginação. Em 2009 voltou a trabalhar, novamente, de maneira informal. Criou seu próprio blog e sua página no Facebook, onde divulga seu trabalho. Entre seus parceiros nessa empreitada, cita a Rede Cidadã e a ABD (Associação Brasileira de Decoração).

Com 47 anos de idade e ensino médio completo, a terceira empreendedora "C" é viúva e mora com seus cinco filhos, com idades de 20,18,16, 15 e 13 anos. Após o casamento, com a chegada dos filhos, ficou difícil para sair de sua casa, localizada no Bairro Veneza, em Venda Nova, e ir trabalhar em Belo Horizonte, onde, anteriormente, havia sido empregada em uma Farmácia. Seu período como vendedora deu-lhe segurança e experiência para lidar com o público, além de conhecer procedimentos que a auxiliaram no momento em que começou a lidar com a venda de seus produtos, chinelos decorativos. Seu negócio, iniciado em 2009, foi um dos projetos apoiados pela Prefeitura de Venda Nova. 
Seu primeiro contato com o ramo de atividade foi por meio de cursos de artesanato, realizados no próprio bairro. Lá, encontrou uma moça que bordava e então se interessou e aprendeu o ofício. Na ocasião, era apenas uma complementação de renda. Com a morte de seu esposo, tendo que sustentar uma grande família, o negócio tornou-se importante fonte de renda, ao lado da pensão do marido. A produção era realizada em sua residência e contava com a parceria de uma amiga. Chegavam a vender, em média, 100 pares de chinelos/mês. O ponto de venda era uma barraca, em um espaço cedido pela Prefeitura supracitada. Sua clientela era formada, em grande parte, por uma rede direta e indireta de conhecidos e amigos, muitos do próprio bairro. Uma vez encerradas as atividades da feira pela Prefeitura, "C" relata que sair de "porta em porta" para vender seu produto seria muito difícil, encerrando assim suas atividades, passando a viver da pensão de seu marido e da renda de trabalhos temporários eventuais.

Com 32 anos de idade, a quarta empreendedora " $D$ " é solteira e mora com os pais na região do Barreiro em Belo Horizonte. Com curso superior completo de enfermagem, trabalha, atualmente, à noite, como enfermeira em hospital público, e, durante o dia, em uma empresa de telefonia. De acordo com seus relatos, a sua renda não era suficiente para sua sobrevivência. Sendo assim, buscou forma de complementá-la, passando a atuar, em 2014, no ramo de cosméticos, como revendedora dos produtos da empresa Mary Kay, vendendo seu produto nos contatos de trabalho, na vizinhança e para clínicas particulares, acessadas através de seus contatos.

Segundo ela, escolheu esta empresa, por ser muito reconhecida no mercado, e que, além disso, gosta muito de trabalhar com questões de beleza. Tal atividade sobreviveu, de maneira sistemática, até meados de 2016. Depois disso, foi sendo desativada, aos poucos. Como conseguiu formar densa rede de relacionamentos pessoais e profissionais, as pessoas continuaram recorrendo a ela, para aquisição dos produtos. Manteve para isso, pequeno estoque em sua casa, que passou a utilizar, de forma não sistemática.

Em suas palavras, sua falta de organização foi um dos principais motivos que a levou a dívidas crescentes e consequente desmotivação. Ela reconhece que não "corria atrás" e não se dedicava o suficiente para o sucesso do negócio. Ela pondera: "Eu acho que é assim, como toda empresa, se você não dedica você não consegue. Eu tinha que vender, que divulgar, e tinha que fazer seções demonstrativas e não fazia." Segundo seu relato, a estabilidade financeira (e pessoal) para ela estava ligada à possibilidade de realizar um concurso público, sonho que conseguiu realizar há cinco anos, quando pôde ingressar como enfermeira em hospital público. O negócio no ramo de cosméticos não era sua prioridade.

É importante a partir deste ponto, resgatarmos evidências empíricas associadas a cada um dos fatores elencados no modelo teórico. Alguns destes fatores merecem análise minuciosa. Entre eles situam-se, dentro da categoria indivíduo, o fator personalidade; dentro da categoria atividade produtiva, os fatores planejamento e gestão; dentro da categoria ambiente sócio econômico, os fatores burocracia (onde insere-se a temática da formalização); competição; clientes; crise econômica.

$\mathrm{Na}$ dimensão indivíduo, observa-se que esses, no caso das ativas, demonstraram comprometimento com suas respectivas atividades. Tal situação talvez se explique devido ao fato das duas empreendedoras ativas dependerem, exclusivamente, de suas respectivas 
atividades para sua sobrevivência, diferentemente das extintas, onde a atividade era vista como possível forma de complementação de renda.

$\mathrm{Na}$ dimensão atividade produtiva, observa-se, nos casos das ativas, um esforço mais sistemático de usar, ainda que de forma incipiente, algumas ferramentas de gestão; ou, mesmo, tentativa de recorrer, ainda que de maneira amadora, ao planejamento.

Na dimensão ambiente sócio econômico, o termo burocracia associa-se, na visão das entrevistadas, diretamente ao tema formalização. Embora todas demonstrem sentir certa rejeição, a empreendedora "A" entende como "mal necessário" para seu crescimento, enquanto a empreendedora " $\mathrm{B}$ " precisou se formalizar quando teve a oportunidade de realizar um trabalho melhor e em maior volume. Já as empreendedoras cujas atividades são vistas como "renda complementar" e cujas atividades foram extintas foram indiferentes quando abordadas sobre este assunto.

A concorrência também foi vista de forma divergente entre os grupos. No grupo das ativas, a concorrência foi abordada de forma respeitosa e colaborativa. Ao contrário, para as empreendedoras cujas empresas foram extintas, a concorrência foi abordada com certo descaso. Para elas, além de não enxergarem a existência dos concorrentes, caso os mesmos existam, não eram passíveis de preocupação, considerando o diferencial e a qualidade dos seus produtos.

Alinhada com a temática da concorrência, abordamos a satisfação dos clientes, pois, naturalmente, o cliente insatisfeito tende a migrar para a concorrência mais próxima. Nesse ponto, o grupo das empreendedoras ativas demonstrou grandes preocupações com esse assunto. A empreendedora "A" relatou a realização de entrevistas sistematizadas em parceria com ONGs que, além de formatarem as entrevistas para os clientes, aplicam, compilam os resultados e encaminham para a empreendedora. Da mesma forma, a empreendedora "B" realiza entrevistas pontuais junto aos clientes, além de acompanhar de forma rotineira os comentários postados nas redes sociais e em seu blog, criados também com esse intuito. Ao contrário, as empreendedoras das atividades extintas não possuíam esse mesmo hábito. A empreendedora "C" não investigava tal satisfação, tendo como "termômetro" apenas se o cliente voltava a procurar por seus produtos. A empreendedora " $\mathrm{D}$ " afirmou apenas que confiava na qualidade dos produtos Mary Kay e acreditava na satisfação dos clientes devido à "fama" da empresa.

Por fim, sobre os efeitos da crise econômica e da situação política na qual o país se encontra, a única empreendedora que alega estar sofrendo os impactos foi a empreendedora "A". Assim, supõe-se que os resultados foram mascarados por situações específicas percebidas durante as entrevistas. No caso da empreendedora " $A$ " a sua resposta vai de encontro ao cenário vivenciado por ela nas feiras. Segundo "A" o "dinheiro sumiu" e as pessoas diminuíram significativamente as compras. No caso da empreendedora "B", o fato de afirmar que a crise não a afetou poderia estar sendo tamponado pelo momento pessoal em que vive, ou seja, ela mesma diminuiu a quantidade de atendimentos devido a uma grave doença da irmã, o que a impede de enxergar se a clientela se afastou por causa da crise. Quanto às empreendedoras "C" e "D", pode-se perceber que a extinção das empresas se deu um pouco de forma simultânea ao aparecimento da crise, o que pode ter ocultado seus efeitos, uma vez que a atividade se encerraria independentemente da crise. 


\section{Considerações Finais}

Este artigo, resultado de pesquisa teórico-empírica, teve o objetivo de investigar as causas de sobrevivência e mortalidade de atividades produtivas informais imersas no segmento de baixa renda, com foco no empreendedorismo feminino. Para isto, investigou a dinâmica de desenvolvimento de quatro empreendimentos informais localizados na região metropolitana de Belo Horizonte, sendo dois ativos e dois extintos. Diferentes observações podem ser destacadas. Em primeiro lugar, a população de baixa renda, especialmente as mulheres, encontra nas unidades produtivas informais caminho alternativo para a inclusão social e para a busca pela subsistência. Se, por um lado, o ciclo da inclusão social se fortalece quando o indivíduo/empreendedor obtém sucesso em seu negócio, por outro, o insucesso tende a retroalimentar o ciclo da pobreza. Tal foi o identificado nos casos estudados.

Em segundo lugar, alguns fatores elencados na literatura acerca dos negócios formais podem, também, serem observados no contexto da informalidade. Inserem-se, aí, o papel da experiência prévia, da personalidade, das redes de relacionamentos, dos recursos da atividade produtiva, sua relação com parceiros, fornecedores, concorrentes, etc. Apesar disto, a maior parte dos fatores salientados na literatura sobre o contexto formal não se demonstrou apropriada de serem aplicados ao contexto informal, dada a natureza muitas vezes precária, irregular e instável dessas atividades. Neste sentido, este estudo, uma inovação no campo da administração, avança na literatura sobre empreendimentos informais ao, de maneira inovadora, projetar luzes sobre dimensões (indivíduo, atividade produtiva e ambiente sócio econômico), ainda não enfatizadas, capazes de contribuir para a compreensão da dinâmica envolvida no desenvolvimento de tais empreendimentos. Tais dimensões devem, obviamente, ser objeto de novos estudos, visando robustecer suas premissas, aqui apenas esboçadas.

Em terceiro lugar, conquanto as três classes de fatores associados à sobrevivência e mortalidade de empreendimentos informais possam, à princípio, serem sugeridas/identificadas e classificadas, estas se encontram, na prática, imbricadas umas às outras. Ou seja, há grande interação entre certos elementos associados às características do indivíduo, à atividade produtiva e ao meio socioeconômico no qual se insere. É assim, por exemplo, que a empreendedora A (e outras) fez de sua casa o local de produção; usou de um bem de consumo pessoal (por exemplo, seu fogão ou geladeira) como bem de produção ou capital; recorreu a vizinhos ou conhecidos como parceiros na divisão dos riscos e benefícios de certas iniciativas produtivas. Ou, então, que as empreendedoras $\mathrm{C}$ e D buscaram seus colegas e conhecidos para acessar clientes, etc. Prevalece nesse segmento, mistura intensa entre dimensões de trabalho/renda, vida pessoal e contexto social, e também, entre trabalho e capital e entre vida social e mercado, etc.

Em quarto lugar, observa-se, nesse segmento, a presença de conceitos diferenciados, distinguindo, entre os empreendedores, a linguagem aí presente daquela manifesta no contexto dos negócios formais. É assim que uma das empreendedoras estudadas refere-se ao conceito de "sobras", ao invés de se referir ao conceito de lucro, por exemplo. Isto é, é possível observar, na essência de vários relatos, a existência de vocabulários próprios e de atitudes eventualmente provenientes da baixa escolaridade e da falta de experiência prévia no mercado formal de trabalho. Tal é evidenciado no caso da distribuição das "sobras", quando a empreendedora afirma que tudo "É divido em partes iguais para todos trabalharem". 
Em quinto lugar, o segmento apresenta uma dinâmica muito diferenciada, que repercute na própria lógica de sobrevivência e mortalidade. Não parece coincidência o fato das duas atividades ativas se constituírem, para os indivíduos envolvidos, na única e exclusiva fonte de renda. Consequentemente, eles não teriam outra opção, a não ser a de se desdobrar para se manterem ativas e garantir sua própria sobrevivência. Tal realidade diferiu daquela conduzida pelos empreendimentos extintos. Nestes, os indivíduos contavam com alternativas de renda, embora precárias.

Em sexto lugar, dados de campo parecem concluir serem as fronteiras entre a informalidade e a formalidade muito tênue, dependente do ambiente e das condições da própria atividade. Com efeito, da mesma maneira que um empreendimento pode se formalizar em momento de relativa expansão ou expectativa favorável, como foi o caso da atividade B, pode, por outro lado, regredir, com certa facilidade, à informalidade de mercado. Durante o processo de seleção dos casos, parte dos contatos preliminares informou terem, devido a crise econômica, sidos obrigados a retomarem às atividades informais, a despeito de fato de as terem encerrado anteriormente. O próprio conceito de atividade ativa ou inativa, sucesso ou fracasso parecem relativos quando analisados no segmento informal.

Este trabalho apresenta contribuições de natureza teórica, com implicações de ordem prática. No campo teórico, ao edificar, de maneira inovadora nos estudos da administração, novo modelo de classificação dos fatores que impulsionam a sobrevivência e a mortalidade de empreendimentos inseridos especificamente no contexto informal. Ao fazer isso, projeta luzes para dimensões, ainda não enfatizadas, capazes de contribuir para a compreensão das motivações que impactam o desempenho de empreendimentos informais, em expansão no país. No âmbito prático, este estudo suscita reflexões capazes de subsidiar políticas públicas de estímulo ao enfrentamento da pobreza, à autonomia da população carente, à inserção da mulher no mercado de trabalho e ao consequente aumento da inclusão social no Brasil.

Novos estudos, teóricos e empíricos, demonstram-se necessários. Eles devem avançar em proposições, aqui iniciadas. Neste sentido, sugere-se investigar: i) Quais os motivos que levam os indivíduos a saírem da informalidade e a retornarem a ela? ii) Quais os perfis das redes mais utilizadas e sua importância no contexto da informalidade? iii) Qual o impacto dos tributos na formalização dos informais? iv) Quais os possíveis impactos de maior apoio técnico e de melhores políticas públicas nas atividades produtivas informais de baixa renda? v) Quais as possibilidades da participação da mulher de baixa renda no empreendedorismo formal e/ou informal? Estes e outros estudos certamente contribuíram para ampliar a atual compreensão sobre o empreendedorismo informal no país e a participação da mulher nesse contexto. Trata-se de uma oportunidade aos pesquisadores da administração, ainda hoje ausentes a esta temática Brasil.

\section{REFERÊNCIAS}

Aaboen, L., Dubois, A., \& Lind, F. (2012). Capturing processes in longitudinal multiple case studies. Industrial Marketing Management, 41(2), 235-246.

Albuquerque, A. F. (2013). Fatores de mortalidade de pequenas empresas: análise de Escola de Engenharia de São Carlos, Universidade de São Paulo, São Carlos, SP. 
Bruschini, Cristina. (2006). Trabalho doméstico: inatividade econômica ou trabalho nãoremunerado?. Revista Brasileira de Estudos de População, 23(2), 331353. https://dx.doi.org/10.1590/S0102-30982006000200009

Cazarini, E. W.; Santos, E. M.; Oliveira Neto, J. D. \& Oliveira, S. R. M. (2008). Fatores de sucesso e insucesso do pequeno empreendedor: um olhar sobre seus tipos de personalidade e estilos de aprendizagem. São Paulo: EGEPE.

Costa, Bianca Lima (2007). Em busca de autonomia: a trajetória de mulheres na Economia Solidária. Dissertação (Dissertação de Mestrado, Pontifícia Universidade Católica de Minas Gerais, Programa de Pós Graduação em Ciências Sociais). Recuperado a partir de http://www.biblioteca.pucminas.br/teses/CiencSociais_CostaBA_1.pdf

Creswell, J. W. (2007). Projeto de Pesquisa: métodos qualitativo, quantitativo e misto (pp. 184-210). Porto Alegre: Artmed.

Dias, C. A.; Gonçalves, R. E.A.\& Augusto, H. A. (2014). Contextualizando a relação natividade versus mortalidade de micro e pequenas empresas no Brasil. In: $8^{o}$ Fórum de Ensino, Pesquisa e Extensão da Unimontes. Montes Claros/MG.

D'incao, M. A. (1997). "Mulher e família burguesa". In: DEL PRIORE, Mary; BASSANEZI, Carla (Orgs.). História das mulheres no Brasil. São Paulo: Contexto/UNESP. p. 223-240. (2017). Publicado originalmente em 1997.

Dutra, I. S.; Previdelli, J. J. (2005). Fatores condicionantes da mortalidade de empresas: um estudo dos empreendedores de micro e pequenas empresas paranaenses. Revista Capital Científico, 3(1), pp. 29-50.

Eckert, A.; Mecca, M. S.; Blasio, R., \& Macari, T. D. (2013). Gestão de pequenas empresas: identificação de mortalidade das empresas em um município da Serra Gaúcha. Revista Escola de Negócios (REN), 1(1), pp. 1-16.

Eisenhart, M. (2009).Generalization from qualitative inquiry.Generalizing from educational research: Beyond qualitative and quantitative polarization, p. 5166.

Ferreira, A. (2009). Favelas no Rio de Janeiro: nascimento, expansão, remoção e, agora, exclusão através de muros. Revista Bibliográfica de Geografia Y Ciências Sociales, 14 (828).

Ferreira, L. F. F.; Santos, S. A.; Oliva, F. L.; Grisi, C. C. H., \& Lima, A. C. (2012). Análise quantitativa sobre a mortalidade precoce de micro e pequenas empresas da cidade de São Paulo. Revista Gestão da Produção, 19(4), pp. 811-823.

Gaskell, G. (2002). Entrevistas individuais e grupais. In M. Bauer, \& G. Gaskell (Eds.), Pesquisa Qualitativa com Texto, Imagem e Som: um manual prático (pp. 64-83). Petrópolis: Vozes

Global Entrepreneurship Monitor- GEM. (2011). Empreendedorismo no Brasil. Acesso em $15 / 09 / 2016$.

:http://www.sebrae.com.br/Sebrae/Portal\%20Sebrae/Anexos/Livro\%20GEM\%20Brasil\%2 02 011.pdf 
Godoy, A. S. (1995). A pesquisa qualitativa e sua utilização em administração de empresas. Revista de administração de empresas, 35(4), 65-71. Recuperado de http://www.scielo.br/pdf/rae/v35n4/a08v35n4.pdf

Godoy, A. S. (2005). Refletindo sobre critérios de qualidade da pesquisa qualitativa. Gestão.Org - Revista Eletrônica de Gestão Organizacional, 3(2), 85-94. Recuperado de http://www.revista.ufpe.br/gestaoorg/index.php/gestao/article/view/136

Godoy, A. S. (2006). Estudo de caso qualitativo. In C. K. Godoi, R. Bandeira-de-Mello, \& A. Barbosa (Orgs), Pesquisa qualitativa em estudos organizacionais: paradigmas, estratégias e métodos (pp. 115-146). São Paulo: Saraiva.

Gomes, A. F. O perfil empreendedor de mulheres que conduzem seu próprio negócio: um estudo na cidade de Vitória da Conquista, BA. Revista Alcance, v. 11, n. 2, p. 207-226, 2004.

Leone, (2010). O perfil dos trabalhadores e trabalhadoras na economia informal no Brasil. Brasília: OIT.

Maia, C. E. S. (1999). Informalidade e Ilegalidade: faces e disfarces na economia urbana. Boletim Goiano de Geografia, 19 (2), pp. 99-117.

Marques, E. C. (2010). Redes sociais, segregação e pobreza. São Paulo: UNESP.

Márquez, P., Reficco, E., \& Berger, G. (2010). Negócios inclusivos: iniciativas de mercado con los pobres de Iberoamérica.

Minayo, M. C. S. de., Souza, E. R. de., \& Santos, N. J. dos. (2005). Avaliação por triangulação de métodos: abordagem de programas sociais (pp. 71-103). Rio de Janeiro: Fiocruz

Montenegro, M. R. (2013). Reflexões para uma teoria da localização da economia de insucesso de projetos de novos empreendimentos: um estudo com dados da Kauffman firm survey. Revista de Gestão e Projetos, 3(1).

Pamplona, J. B., \& Romeiro, M. C. (2002). Desvendando o setor informal: relatos de uma experiência brasileira. Revista da ABET, 2(22).

Perrot, Michelle. Minha história das mulheres/[tradução Angela M. S. Côrrea]. - 2. ed., $5^{\circ}$ reimpressão. - São Paulo: Contexto, 2017a.

Perrot, Michelle. Os excluídos da história: operários, mulheres e prisioneiros. $7^{\mathrm{a}}$ ed. Rio de Janeiro/ São Paulo, Paz e Terra, 2017b.

Pochmann, M. (2008). O emprego no desenvolvimento da nação. São Paulo: Boitempo.

Portes, A., \& Schauffler, R. (1993). De la mano de obra excedente a la empresa dinâmica: perspectivas de competência del sector informal latinoamericano. Estudios Sociológicos, 11(33), pp. 817-850.

Rago, M. Trabalho Feminino e sexualidade. In: PRIORI, M. Del (Org.). História das mulheres no Brasil. 10. ed., $5^{\circ}$ reimpressão - São Paulo: Contexto, 2017. p. 578 a 606. 
Rakowski, C. A. (1994). Convergence and Divergence in the Informal Sector Debate: a Focus on Latin America, Ohio State University: Columbus.

Rede Cidadã. (2015). Voluntários em Rede: guia de apoio ao mentor voluntário, Belo Horizonte/MG.

Relatório anual do Banco Mundial (2015). Recuperado em 30/04/2016 de: https://openknowledge.worldbank.org/bitstream/.../WBAnnualReport2015PT.pdf.

Ridder, H., Hoon, C., \& McCandless, A. (2009). The theoretical contribution of case study research to the field of strategy and management. Research Methodology in Strategy and Management, 5, 137-175.

Santos, A. L. (2006). Trabalho em pequenos negócios no Brasil: impactos da crise do final do século XIX. (Tese Doutorado). Instituto de Economia, Universidade Estadual de Campinas, Campinas.

Santos, A. L.; Krein, J.D.; Calixtre, A. B. Org. (2012). Micro e pequenas empresas: mercado de trabalho e implicação para o desenvolvimento, Rio de Janeiro: Ipea.

Santos, C. M. M. As mulheres brasileiras: do espaço privado da casa para as posições executivas nas organizações brasileiras. (2012) Tese. Pontifícia Universidade Católica de MG, Belo Horizonte.

Santos, J. B. F.; Maciel, R.H.M.O.; Sato, L., \& Santos, J. B. F. (2014). Trabalhadores informais e a formação de redes socioprodutivas (RSP): considerações teórico-empíricas. Revista Contemporânea, 2(4).

Sen, A. K. (2010). Desenvolvimento como liberdade. São Paulo: Companhia das Letras.

Serviço Brasileiro de Apoio às Micro e Pequenas Empresas - SEBRAE (2011). Dez anos de monitoramento da sobrevivência e mortalidade de empresas. São Paulo: SEBRAE/SP.

Theodoro, M. (2000). As bases da política de apoio ao setor informal no Brasil. Brasília: IPEA. Valarelli, M. M., \& Vale, G. M. V. (1997). Informalidade e cidadania: empreendimentos informais no Rio de Janeiro. Rio de Janeiro: IBASE.

Valarelli, M. M., \& Vale, G. M. V. (1997). Informalidade e cidadania: empreendimentos informais no Rio de Janeiro. Rio de Janeiro: IBASE.

Vale, G. M. V., Aguiar, M. A. S., \& Andrade, N. A. (1998). Fatores condicionantes da mortalidade de empresas.vale Brasília: Edições Sebrae.

Vianna, M. O. S.; Teixeira, R. M., \& Franca, V. V. (2013). Perfil dos empreendedores individuais e características dos negócios formalizados pelo programa EI em Aracaju, Sergipe. Revista Pensamento Contemporâneo em Administração, Rio de Janeiro, 7 (2), pp. $19-40$.

Warren, I. S. (2003). A problemática da pobreza na construção de um movimento cidadão. Revista Política e Sociedade, 2(3).

Yin, Robert K. (2010). Estudo de caso: Planejamento e métodos. (5a ed.). Porto Alegre: Bookman. 